\title{
Neuroinvasive Phlebovirus Infection in Greece: A Case Report
}

\author{
Anna Papa $^{a}$ John Mallias ${ }^{b}$ Katerina Tsergoulia Fani Markouc ${ }^{c}$ Ageliki Poulou $^{c}$ \\ Theodor Milidis ${ }^{b}$ \\ aDepartment of Microbiology, Medical School, Aristotle University of Thessaloniki, Thessaloniki, and \\ b2nd Internal Medicine Clinic, and 'Department of Microbiology, General Hospital of Serres, Serres, Greece
}

\section{Key Words}

Phlebovirus · Toscana virus · Greece

\begin{abstract}
Objective: Sandfly fever phleboviruses are endemic in Mediterranean countries. We report a febrile phlebovirus case in a Greek patient who presented signs of neuroinvasive infection. Methods: In summer 2010, a 20-year-old male was admitted to hospital with fever and lethargy; he was a resident of central Macedonia, northern Greece, where a large outbreak of West Nile virus (WNV) infections occurred at that time. Since there was no laboratory evidence of WNV infection, the patient's serum and cerebrospinal fluid were tested for a probable phlebovirus infection. Results: High titers of IgM and IgG antibodies against Toscana virus were detected in serum and cerebrospinal fluid, while the titers against sandfly fever Naples virus were lower; no reactivity was detected against sandfly Sicilian and Cyprus viruses. Since neutralization assays were not performed and PCR resulted in being negative, it was concluded that the causative agent was a phlebovirus of the sandfly fever Naples serocomplex. Conclusion: The present case confirms results from previous seroprevalence studies showing that phleboviruses of the sandfly fever Naples serocomplex are present in Greece and
\end{abstract}

provides evidence that they cause febrile neuroinvasive disease in humans, prompting for inclusion of phleboviral infections in the differential diagnosis of acute febrile cases during the time when sandflies are active.

C 2014 S. Karger AG, Basel

\section{Introduction}

Sandfly fever phleboviruses (family Bunyaviridae) are endemic in Mediterranean countries causing an asymptomatic or mild infection in humans. One of them, Toscana virus (TOSV), has the potential to cause a neuroinvasive disease (meningitis or meningoencephalitis) [1]. The outcome of TOSV infections is usually favorable without sequelae, however severe and even fatal cases have been reported $[2,3]$. In central Italy, TOSV is the most frequent cause of meningitis from May to October in both children and adults $[4,5]$.

Recent studies in the Greek population have shown that the prevalence of IgG antibodies against TOSV or antigenically related phlebovirus(es) is high (up to 50\%), especially on the islands and coastal areas of the mainland [6-8]. A TOSV seroconversion was reported in 1993 in a German traveler returning from Greece [9]. These results

\section{KARGER}

E-Mail karger@karger.com

www.karger.com/int
(C) 2014 S. Karger AG, Basel

0300-5526/14/0576-0393\$39.50/0
Prof. Anna Papa, MD, PhD

Department of Microbiology, Medical School

Aristotle University of Thessaloniki

GR-54124 Thessaloniki (Greece)

E-Mail annap@med.auth.gr 
suggested that phleboviruses of the sandfly fever Naples (SFN) serocomplex, to which TOSV belongs, are widely present in Greece. Up until now, 2 cases of phlebovirus infections have been described in Greece; however, both of them were TOSV-IgM-negative: an 8-year-old boy with meningoencephalitis in whom TOSV IgG seroconversion was observed, and a febrile child in whom a novel phlebovirus (Adria virus) was detected by PCR [10,11]. It is very likely that many phlebovirus infections remain unrecognized, either because they are asymptomatic or mild, or because clinicians do not include phleboviral infections in the differential diagnosis of febrile or neurological syndromes.

\section{Case Presentation}

The summer of 2010 was critical for Greece, since West Nile virus (WNV) emerged in the country and caused a large outbreak of human infections [12]. That time, a previously healthy 20 -yearold male farmer was admitted to the General Hospital of Serres because of 3-day fever $\left(38^{\circ}\right)$ and lethargy. He was resident in a village $12 \mathrm{~km}$ west from Serres, in central Macedonia, northern Greece, and did not mention having travelled abroad. On admission his blood pressure was $105 / 80 \mathrm{~mm} \mathrm{Hg}$, with a heart rate of 95 beats/min and $97 \%$ oxygen saturation. Main laboratory findings were a white blood cell count of 6,190 cells $/ \mathrm{ml}$ (53\% neutrophils, $37 \%$ lymphocytes, $8 \%$ monocytes, $2 \%$ eosinophils), hematocrit $42.2 \%$, platelets $135,000 / \mathrm{ml}$, erythrocyte sedimentation rate 21 $\mathrm{mm} / \mathrm{h}$, and C-reactive protein $0.99 \mathrm{mg} / \mathrm{l}$. The patient did not present any focal neurological signs or neck stiffness. Although he was oriented in time and place, he was lethargic with bradypsychia and photophobia.

The patient's cerebrospinal fluid (CSF) was clear and colorless, with 60 cells $/ \mathrm{mm}^{3}$ (70\% lymphocytes, 30\% neutrophils), and glucose and protein levels of 52 and $71 \mathrm{mg} / \mathrm{dl}$, respectively. CSF culture was negative for common bacteria. No abnormalities were seen in brain CT and MRI. The patient was given ceftriaxone $(2 \mathrm{~g}$ $\times 1)$, acyclovir $(750 \mathrm{mg} \times 3)$, mannitol and dexamethasone $(4 \mathrm{mg}$ $\times 2$ ). On hospitalization day 2 the patient became afebrile and on day 4 he recovered completely and was discharged. Six months later he was clinically re-tested and was found free of symptoms.

Given that cases of WNV infection had been reported in Serres regional unit, the patient's serum and CSF samples obtained upon admission were sent to the National Reference Centre for Arboviruses in Thessaloniki, for testing for a probable WNV infection. Since there was no laboratory evidence of WNV infection, the samples were further tested by indirect immunofluorescent test (IFA) for the detection of IgM and IgG antibodies against four phleboviruses: TOSV, SFN virus (SFNV), sandfly fever Sicilian virus (SFSV) and Cyprus virus (CYPV) (Sandfly fever virus Mosaic 1; Euroimmun, Lübeck, Germany). A commercially available ELISA was also used for the detection of TOSV-specific IgM and IgG antibodies (EIA Enzywell Toscana virus IgG and IgM; Diesse Diagnostica Senese SpA, Siena, Italy). Viral RNA was extracted from the patient's CSF sample and an RT-nested PCR was applied using phlebovirus generic primers [13].
High titers (serum dilution 1:1,000) of IgM and IgG antibodies against TOSV were detected by IFA in both serum and CSF, with tenfold lower titers against SFNV; no reactivity was detected against SFSV and CYPV. IgM antibodies reacting against TOSV antigen were also detected in both serum and CSF samples using ELISA (index in serum: 3.82 ; index in CSF: 4.5 ; cutoff: 1.2 ). Phlebovirus RNA was not detected.

Phleboviruses in the same serocomplex exhibit close genetic and antigenic relationships. Our patient presented highest levels of IgM and IgG antibodies against TOSV, and lower levels against the related SFNV, while no reactivity was seen against SFSV and CYPV which belong to a different serocomplex. Neutralization assays enable the discrimination among phleboviruses within a serocomplex; however, in order to be accurate, a panel of phleboviruses (including several newly identified) has to be used. A positive PCR would enable us to identify the exact virus strain; however, it was negative, probably due to the low level and short time viremia associated with phlebovirus infections, or to due to the damage of RNA during the transportation of samples without dry ice (since they were sent for WNV serology). The IFA results, together with the detection of IgM antibodies reacting with TOSV antigen (nucleoprotein) in ELISA, suggest that a phlebovirus of SFN serocomplex, probably TOSV, was the causative agent of the disease.

\section{Conclusion}

The present case report confirms the results of previous seroprevalence studies that phleboviruses of the SFN serocomplex are present in Greece, and provides evidence that they cause febrile neuroinvasive disease in humans, prompting for increased awareness by physicians to include phlebovirus infections in the differential diagnosis of summer acute febrile cases, combined or not with neurological symptoms. Further field and clinical studies are needed to elucidate the complex epidemiology of phleboviruses in the Mediterranean area.

\section{Acknowledgement}

The National Reference Laboratory for Arboviruses is financially supported by the Hellenic Centre for Disease Control and Prevention.

\section{Disclosure Statement}

The authors have no conflicts of interest to disclose. 


\section{References}

1 Charrel RN, Gallian P, Navarro-Mari JM, Nicoletti L, Papa A, Sanchez-Seco MP, Tenorio A, de Lamballerie X: Emergence of Toscana virus in Europe. Emerg Infect Dis 2005;11: 1657-1663.

-2 Baldelli F, Ciufolini MG, Francisci D, Marchi A, Venturi G, Fiorentini C, Luchetta ML, Bruto L, Pauluzzi S: Unusual presentation of lifethreatening Toscana virus meningoencephalitis. Clin Infect Dis 2004;38:515-520.

-3 Bartels S, de Boni L, Kretzschmar HA, Heckmann JG: Lethal encephalitis caused by the Toscana virus in an elderly patient. J Neurol 2011;259:175-177.

4 Braito A, Corbisiero R, Corradini S, Fiorentini C, Ciufolini MG: Toscana virus infections of the central nervous system in children: a report of 14 cases. J Pediatr 1998;132:144148.
-5 Braito A, Ciufolini MG, Pippi L, Corbisiero R, Fiorentini C, Gistri A, Toscano L: Phlebotomus-transmitted Toscana virus infections of the central nervous system: a seven-year experience in Tuscany. Scand J Infect Dis 1998;30: 505-508.

6 Anagnostou V, Papa A: Prevalence of antibodies to phleboviruses within the sandfly fever Naples virus species in humans, northern Greece. Clin Microbiol Infect 2013;19:566570.

7 Anagnostou V, Papa A: Seroprevalence of Toscana virus among residents of Aegean Sea islands, Greece. Travel Med Infect Dis 2013; 11:98-102.

-8 Papa A, Andriotis V, Tzilianos M: Prevalence of Toscana virus antibodies in residents of two Ionian islands, Greece. Travel Med Infect Dis 2010;8:302-304.

-9 Dobler G, Treib J, Haass A, Frosner G, Woesner R, Schimrigk K: Toscana virus infection in German travelers returning from the Mediterranean. Infection 1997;25:325.
10 Anagnostou V, Pardalos G, AthanasiouMetaxa M, Papa A: Novel phlebovirus in febrile child, Greece. Emerg Infect Dis 2011;17: 940-941.

11 Anagnostou V, Sdouga M, Volakli H, Violaki A, Papa A: Phlebovirus meningoencephalitis complicated by Pseudomonas aeruginosa pneumonia: a case report. Vector Borne Zoonotic Dis 2010;11:595-596.

12 Papa A, Danis K, Baka A, Bakas A, Dougas G, Lytras T, Theocharopoulos G, Chrysagis D, Vassiliadou E, Kamaria F, Liona A, Mellou K, Saroglou G, Panagiotopoulos T: Ongoing outbreak of West Nile virus infections in humans in Greece, July-August 2010. Euro Surveill 2010;15:19644.

13 Sanchez-Seco MP, Echevarria JM, Hernandez L, Estevez D, Navarro-Mari JM, Tenorio A: Detection and identification of Toscana and other phleboviruses by RT-nested PCR assays with degenerated primers. J Med Virol 2003; 71:140-149. 